\title{
Arbor
}

\section{Vida, fulgor y crisis del sistema escolar español}

\section{Julio Ruiz Berrio}

Arbor CLXXIII, 681 (Septiembre 2002), 83-102 pp.

Los sistemas escolares nacionales han entrado en crisis, tras los cambios científicos, tecnológicos, informáticos, de aprendizaje, de producción de conocimiento, de nuevos modelos de educación, etc., que han tenido o están teniendo lugar en el mundo. A la vez hay que desmitificar falsas identificaciones en ellos como «sistema escolar» $y$ «educación», por ejemplo. Es la hora de revisarlos, bien para sustituirlos o bien para reorientarlos correctamente. Pero para decidir mejor sobre su porvenir es aconsejable recordar su biografía. Por ello en este trabajo se hace una rápida revisión histórica del sistema escolar español, contemplado en cuatro fases decisivas de su vida: las de su génesis, su consolidación, sus reformas y su crisis.

En este mismo año de 2002, en el mes de julio, va a celebrarse en la universidad de Londres un coloquio cuyo tema general es una interrogante sobre el fin de los sistemas escolares. Está organizado por la Sociedad europea de Educación Comparada, y se trata de su vigésimo congreso, lo que significa de entrada una competente organización científica internacional y una perspectiva mundial del problema, que autorizan a pensar en la pertinencia e interés de tal debate.

Por supuesto que en estos meses previos no podemos saber la contestación que los especialistas darán a la gran pregunta, pero en cambio sí que podemos afirmar ya que la crisis ${ }^{1}$ en que han entrado los sistemas escolares nacionales en los diez o veinte últimos años es real, tangible, y avanza de modo imparable. Es debida a causas tan diversas como el cre- 
cimiento económico, el desarrollo de la sociedad de la información, los nuevos procesos de socialización del individuo, los nuevos lugares de aprendizaje, la diversidad de agencias educativas, la utilización de las nuevas tecnologías, los nuevos modelos de educación, la producción del conocimiento, o el avance de la globalización (por supuesto que hay que poner en marcha «las otras globalizaciones», como dice Federico Mayor Zaragoza). A esos y otros factores de cambio, de nuevo escenario, en España hay que añadir además el de la nueva estructura política y administrativa que supone la existencia y funcionamiento de las Comunidades Autónomas. En fin, todo ello colabora a un replanteamiento de los sistemas escolares, empezando por el que se ha iniciado en los estudios de Educación Comparada, hasta ayer preocupados en exceso por tales sistemas y hoy decididos a dejarlos en un segundo o tercer plano, para ceder el paso al análisis comparativo de problemas educativos y pedagógicos en espacios más amplios que las naciones clásicas.

Pero, justamente porque es la hora de revisar qué hacemos con los sistemas escolares, es también un momento muy adecuado para echar una ojeada a la historia de sus características, intentando reconstruir su génesis, los contextos de su consolidación, las notas de su desarrollo, la evolución temporal de sus objetivos, las principales reformas, la falsa identificación entre sistema escolar y educación, etc., en una palabra, de reconstruir su memoria; lo que se puede hacer de modo resumido. Y si esto conviene en general a muchos de los sistemas, estimo que es muy procedente en el caso del sistema escolar español, un sistema escolar de y para una sociedad compleja.

\section{Génesis}

La génesis del sistema escolar español se efectuó en España mediante procesos semejantes a los de otros países europeos ${ }^{2}$, y en un tiempo paralelo, aunque no exacto, ya que la configuración definitiva de ese sistema se retrasó un par de décadas debido a la oposición frontal de Fernando VII a un régimen constitucional. Unido ello a los años que fueron necesarios para lograr el consenso para una ley general, nos lleva a mantener que el sistema educativo español quedó instituido sólidamente en un tiempo tan amplio como el que va de las Cortes de Cádiz ${ }^{3}$ a la promulgación de la primera Ley general de Instrucción Pública en España ${ }^{4}$.

Como bien puso de relieve el historiador francés F. Braudel en su día, la historia no cambia de la noche a la mañana, de unos días para otros, por hechos singulares o accidentales, sino que se va configurando a 
través de procesos de larga duración. Ello nos ayudará a comprender en nuestro caso que, bastante antes de que las Cortes reunidas en Cádiz debatieran y aprobaran una serie de cambios de signo social, económico, político, educativo, etc., se había iniciado un proceso de renovación de la sociedad española en distintos órdenes, aunque, como es lógico por su carácter antecedente, sin conseguir resultados efectivos ni alcanzar metas concretas. Pero es ahí, en la etapa reformista de los ilustrados, en la segunda mitad del siglo XVIII, donde encontramos los primeros pasos que se dan en España hacia un sistema escolar.

Desde un régimen despótico, las minorías ilustradas en el poder intentaron regenerar el país a partir de un planteamiento económico que exigía la liberación del comercio, de los precios o de las producciones, el levantamiento de los monopolios, la creación de una infraestructura viaria nacional, la modernización de los puertos, la renovación de la agricultura y la ganadería, o el desarrollo de la industria. Para llevar adelante una política de tales características las autoridades consideraron necesario el aumento de los derechos y prerrogativas del poder civil ${ }^{5}, \mathrm{y}$ por ello su administración tuvo un sello claramente uniformador, centralista, secularizador, sacrificando la autonomía de que gozaban muchas instituciones, regiones, personas, en aras de la modernización del país. Por otra parte, como fieles creyentes en el poder de la instrucción ${ }^{6}$, estimaron que aquellos procesos de renovación serían más eficaces y alcanzarían antes sus metas promoviendo las ciencias, las técnicas, las letras y las artes, a la par que extendiendo la instrucción elemental a todos los habitantes, con el doble objeto de que fueran trabajadores con una mínima cualificación y personas virtuosas y felices.

Y para conseguir esta promoción y difusión del saber aquellos políticos pusieron en marcha una serie de reformas científicas y escolares que por su distanciamiento de la realidad social, económica y cultural de la nación, así como por su elaboración autoritaria, se quedaron en muchas ocasiones en meros proyectos. Primero se intentó la reforma de la institución docente por excelencia en aquellos tiempos, la universidad, en el convencimiento de que una vez modernizada sería el mejor motor para la renovación de otras enseñanzas y de la ciencia y la técnica. Pero la fiscalización estatal de toda la vida universitaria que se legisló por una Real Cédula de marzo de 1769, provocó de momento efectos contrarios, y los grupos más reaccionarios y retrasados se defendieron mediante la resistencia pasiva, animada y sostenida por los cuerpos y escuelas que llevaban más de dos siglos dictando sus lecciones y sus privilegios. Los nuevos $-\mathrm{y}$ verdaderamente actualizados- planes de estudio cuyas directrices se impusieron a los claustros no fueron cumplidos, sirviendo sólo para 


\section{Julio Ruiz Berrio}

que el profesorado joven y los alumnos conocieran qué ciencias se estudiaban en otras universidades de Europa, qué metodología se seguía en su enseñanza, qué manuales se habían hecho en aquellas décadas, qué temas eran los que centraban los debates científicos del momento.

Más tarde se aceleró la actividad legislativa en torno a las escuelas de Gramática y a las de primeras letras, con medidas que iban desde una obligada reconversión de los antiguos gremios profesionales ${ }^{7}$ en pretendidas nuevas academias ${ }^{8}$ hasta el establecimiento de un currículo, de unos requisitos para ejercer el magisterio desde instancias nacionales, o de la indicación gubernamental de libros adecuados para la lectura en la escuela, pasando por la elaboración de Ordenanzas para los preceptores de Latinidad y Humanidades o por decretar de forma indirecta la obligatoriedad escolar ${ }^{9}$. Medidas, unas y otras, que en su mayoría no alcanzaron los objetivos previstos en los reinados de Carlos III y Carlos IV, pero que adelantaron las preocupaciones nacionales por el saber y la enseñanza, y que mentalizaron en una nueva perspectiva de sociedad, política, cultura y educación a un sector más amplio de la población española, cada vez más dispuesto a sacar a España del oscurantismo, de la ignorancia, del despotismo, en una palabra, de un régimen sometido a los privilegios de algunos estamentos.

El paso del Antiguo Régimen al orden constitucional en España fue lento y complicado. Por diversas razones, unas personales y otras de grupos, no se logró definitivamente hasta casi mediado el siglo XIX, lo que terminó originando un Estado liberal muy centralista y estatalizador, pero poco liberal. Características que reflejan las ambiciones de las fuerzas sociales predominantes y que condicionaron en un sentido determinado el sistema escolar (Puelles 1997, pp. 35-67) que al final quedaría configurado.

Ahora bien, ese sistema "de Instrucción Pública» se había diseñado por primera vez en una situación histórica especial, de guerra, de la guerra contra las huestes napoleónicas, que tuvo también facetas de guerra civil ${ }^{10}$ entre nosotros y que permitió a las Cortes legislar con bastantes márgenes de libertad porque no se apreciaba otro poder (aparte el del gobierno intruso) que el suyo. Recordemos que, constituidas las Cortes en Cádiz, se instauró el principio de la soberanía nacional y se estableció la división de poderes, se procedió a la abolición del régimen señorial ${ }^{11}$ y se suprimió el Tribunal del Santo Oficio, mientras que se declara la libertad de imprenta entre otras medidas de cambio. Y en 1812 se pudo proclamar la Constitución, basada en esa idea de la soberanía nacional, y que consideraba la educación como una tarea principal de la nación a la vez que exigía un sistema escolar nacional. Por ello no nos debe extrañar 
que esa Constitución dedicara un título entero -por única vez en nuestra historia-, el IX, a la Instrucción pública.

En él se mandaba abrir una escuela de primeras letras «en todos los pueblos de la Monarquía», para enseñar a leer, escribir y contar, a la vez que las verdades cristianas del Catecismo y una síntesis de las «obligaciones civiles». Se creaba un organismo nacional para todos los ramos de la enseñanza, la 'Dirección General de Estudios', y se decretaba la uniformidad en esa instrucción pública, encargando a las Cortes y a la mencionada Dirección el desarrollo de estos artículos y la estructuración de aquella. Estrategias y acciones que a nuestros ilusionados doceañistas les parecieron suficientes para superar en poco tiempo la situación calamitosa en que se encontraba España respecto a su índice de alfabetización (en torno al diez o quince por ciento) y de cultura básica, por lo que en la misma Constitución insertaron otro artículo, el 25, en un título diferente, advirtiendo a los españoles de que «desde 1830 deberán saber leer y escribir los que de nuevo entren en el ejercicio de los derechos de ciudadano». ¡Y no nos podemos olvidar de que para aquellos liberales la ciudadanía era el valor supremo! Dicho de otra modo, soñaron con que en dieciocho años exactamente habrían alfabetizado a unos diez millones de personas, y eso antes de organizar instituciones, formar profesorado, arbitrar medios económicos, etc., o aún peor, antes de diseñar el mismo sistema de instrucción pública.

Muy pronto, de acuerdo con aquel encargo de las Cortes, el Gobierno encomendó a una comisión de sabios, presidida por Manuel José Quintana, un documento sobre la organización de los estudios públicos. Y así nació el Informe de la Junta creada por la Regencia para proponer los medios de proceder al arreglo de los diversos ramos de instrucción pública (M.E.C. 1979, I, pp. 370-414), de fecha 9 de septiembre de 1813. En él se parte de que la nación ha recobrado su soberanía y ello exige un «sistema de instrucción pública digno y propio de un país libre». La instrucción nos enseña cuáles son nuestros derechos y «nos manifiesta las obligaciones que debemos cumplir», y su objetivo es hacer de cada español un perfecto ciudadano, persiguiendo un régimen constitucional, que es el que se entendía que correspondía a un pueblo libre y civilizado. Se esperaba de la instrucción que indicara el puesto que cada uno debería ocupar en la sociedad, y se insistía en que «su objeto es que vivamos felices para nosotros» al tiempo que "seamos útiles a los demás». En consecuencia se debía organizar una instrucción igual y completa, universal (a todos y de todo), uniforme, pública, gratuita y libre, e impartirse en castellano. Creo que así se ponía de manifiesto lo que afirmaba hace pocos meses el historiador Álvarez Junco (2001, p. 545), que «ningún mecanismo era tan 


\section{Julio Ruiz Berrio}

necesario para la construcción nacional como algo que constituía, además, un servicio público: un sistema educativo estatal, obligatorio y gratuito».

Se contemplan tres niveles de enseñanza: primera, segunda y tercera. Y se instituye una Universidad Central en la que se cursarán todos los conocimientos en su máximo grado. Además habrá una enseñanza profesional y técnica, a impartirse en las 'Escuelas particulares'. En la cúspide del edificio del saber figuraría la Academia Nacional, que haría las funciones de lo que hoy denominamos Instituto de España. Al frente de toda la instrucción pública estaría un organismo administrativo, la Dirección General de Estudios. Un agujero negro destaca entre otros en este Informe, el de no contemplar a la mujer en el sistema.

Se disponía que hubiera una escuela primaria por cada quinientos vecinos, o una en cada pueblo si es que aquel la podía sostener; pero no se reflejaría este nivel de enseñanza en los presupuestos del Estado, como en cambio pasaría con la instrucción secundaria y la universitaria. No obstante se indicaron unos contenidos a impartir por esa escuela: leer con sentido, escribir con claridad y buena ortografía, reglas elementales de aritmética, dogmas de la religión y máximas de buena crianza, y los principales derechos y obligaciones de un ciudadano. Si alguna población tuviera medios para abrir también una escuela para muchachos mayores, añadiría a los conocimientos mencionados otros de carácter aplicado. Los maestros posibles quedarían habilitados mediante un examen hecho en las capitales de provincia.

La segunda enseñanza, concebida para «preparar el entendimiento de los discípulos para entrar en el estudio de aquella ciencias que son en la vida civil objeto de una profesión liberal», y para "sembrar en sus ánimos la semilla de todos los conocimientos útiles y agradables que constituyen la ilustración general de una nación civilizada», pasó a ocupar un puesto muy importante en el sistema escolar, convirtiéndose a la vez en un poderoso instrumento de clasismo, al servicio de la clase social que lideraba el cambio en España y en Europa: la burguesía. El currículo se agrupaba en torno a tres núcleos de conocimientos: los de Física y Matemáticas (teóricos y aplicados), los de Literatura y Artes, y los de Ciencias morales y políticas. Habría un centro de segunda enseñanza en cada capital de provincia, que recibiría el nombre de 'universidad de provincia' (son los centros que a partir del Plan del Duque de Rivas se bautizaron como 'institutos').

La tercera enseñanza debería impartirse en las 'Universidades mayores', que quedaban limitadas a nueve en la Península y una en Canarias. Sus estudios se reducían a Derecho y Teología. Los de Medicina pa- 
saban a estimarse como propios de 'Escuelas particulares', como los de Veterinaria, Farmacia, Comercio, Navegación, etc. En pleno apogeo de la competencia profesional asegurada mediante la selección escolar, las cátedras se otorgarían únicamente mediante oposición.

Es cierto que el Informe de Quintana debe mucho a Condorcet, tanto el del Rapport como, lo más importante, el de las Memorias (Condorcet 2001), hasta el extremo de reconocerse en el Informe que se apoya bastante en el filósofo-matemático francés (Condorcet 2001, pp. 16-39). Es más, en un cotejo literal de los dos documentos, se constata la existencia de cuatro grandes párrafos copiados por Quintana, a la vez que diversos principios, orientaciones y convoyes semánticos. Pero en ese seguimiento del plan de Condorcet lo fundamental es que el Informe se inspira en el pensamiento político, filosófico y científico del francés, así como en la utilización del diseño de la organización de los estudios públicos. Sin embargo, hay notables diferencias entre el Informe y el Rapport (Condorcet 2001, pp. 231-338), como lo son la estatalización de la enseñanza que favorece Quintana frente al rechazo frontal de la misma que condiciona el plan de Condorcet; o la ausencia de un plan de igualdad de oportunidades en el español frente al esbozo de un plan de protección a los «alumnos de la patria» en Condorcet; o la presencia de una sensibilidad especial respecto a la educación popular mediante las conferencias semanales en el caso del Rapport, o, para no alargarnos más, la despreocupación por la mujer que se da en el Informe frente al valor concedido a la instrucción de la mujer y a sus capacidades que inspiran al revolucionario francés. En fin, creo que Quintana, en sus principios como en su diseño, tiene en cuenta las aportaciones que sobre la instrucción y política se hicieron en los veinte años que separan un plan de otro, y, sobre todo, se ajustó a las limitaciones que le imponían la Constitución de 1812 por un lado, y la realidad ideológica, económica, política e histórica de España por otro. Además, para 1813 Quintana no sólo conocía el plan de Condorcet, sino también otros muchos -entre ellos el de Tayllerand-de los que se elaboraron durante los diversos periodos de la Revolución francesa, así como durante el Consulado y el Imperio.

Por otra parte, Quintana recibió también la influencia de varios reformistas españoles contemporáneos, como Jovellanos, Alberto Lista, José de Vargas y Ponce, Meléndez Valdés, Narganes, Cabarrús, Marchena, etc., tanto en sus presupuestos filosóficos y políticos como en algunos de sus escritos, especialmente los que recogían intentos de organizar la instrucción pública en España, como la Memoria sobre educación pública (1802) y las Bases para la formación de un Plan general de Instrucción pública (1809) de Jovellanos (1963), la Carta segunda sobre los obstácu- 
los de opinión y el medio de removerlos con la circulación de luces y un sistema general de educación (1802), de Cabarrús (Negrín 1979), o las Tres cartas sobre los vicios de la instrucción pública en España (1809), de Narganes de Posada (Ruiz Berrio 1983 y 1984).

La verdad es que así quedó articulado el edificio de la enseñanza pública en España, prefijándose ya tanto la mayor parte de nuestras instituciones docentes actuales como el tipo y grado de saberes a impartir. En 1814 una Comisión dio expresión jurídica al Informe, convirtiéndolo en Proyecto de Decreto (Ruiz Berrio 1970). Pero la abolición del régimen constitucional y la persecución de los liberales por Fernando VII impidió que se sometiera a las Cortes. Fue siete años más tarde, durante el paréntesis del Trienio liberal, cuando su expresión legal, como Reglamento general de Instrucción Pública (M.E.C. 1979, II, pp. 43-60), fue aprobada; reglamento que se tomó como punto de partida para el desarrollo del sistema y de la administración escolares en los debates y decisiones posteriores a 1834, una vez que el Liberalismo asumió el poder de forma definitiva.

\section{Consolidación}

Superado definitivamente el Antiguo Régimen en 1834, los gobiernos liberales se preocuparon por el desarrollo del sistema escolar en España ${ }^{12}$, para lo que fueron dictando o aprobando diversos planes de estudio, reglamentos, nuevas instituciones docentes ${ }^{13}$, organigramas de la administración escolar, etc., disposiciones que unas veces superaban unas a otras o en ocasiones llegaban a contradecirse, según el grado de variación política de unos gobiernos a otros. Iban buscando todos ellos la promulgación de una ley general que facilitara la regulación y el control de la enseñanza en todos sus niveles, pero las circunstancias, y los vaivenes políticos, fueron limitando sus ambiciones a la aprobación de planes de estudio para un nivel de enseñanza solamente; es más, en muchas ocasiones fueron los «arreglos» para una situación de emergencia como era la proximidad del comienzo de curso los que resolvieron aquel nivel de enseñanza durante tres o cinco años.

De toda esa literatura legislativa merece la pena recordar tres planes por diversas singularidades de cada uno. El primero de ellos, cronológicamente hablando, fue el Plan general de Instrucción Pública ${ }^{14}$, en 1836 (M.E.C. 1979, II, pp. 118-144), en el que se define la enseñanza secundaria como los estudios «que son necesarios para completar la educación de las clases acomodadas» y se introduce en la literatura española el térmi- 
Vida, fulgor y crisis del sistema escolar español

no «Instituto» para designar al centro donde se imparten tales estudios; se fundan las Escuelas Normales para maestros y una Normal específica para profesores de secundaria ${ }^{15}$; y se crea un «Consejo de Instrucción pública».

En 1838 se ordenó el segundo, un «Plan de instrucción primaria planteado provisionalmente», en donde se sientan las bases de la institucionalización de la enseñanza primaria, se legalizan las escuelas de adultos y se crean las escuelas de párvulos. Su inspiración se debe a Pablo Montesino, que al desarrollar el plan mediante un Reglamento (M.E.C. 1979, II, pp. 155-190) nos dejó el documento pedagógico más importante del siglo XIX. El tercer plan a destacar es el Plan General de Estudios ${ }^{16}$ de 1845 (M.E.C. 1979, II, 191-239), ocupado en regular solamente la enseñanza media y la universitaria, por el que su autor, Antonio Gil de Zárate (Viñao 1996), representante típico de los afanes burgueses, caracterizó definitivamente nuestro sistema escolar como secular, centralista (Naval 1999) y uniforme (Puelles 1991), dejando su administración y control de una vez para siempre en manos del Estado. Por supuesto, declara la libertad de enseñanza, permitiendo la creación de centros privados, pero entiende que el permiso correspondiente lo debe otorgar el Estado, como expresión y reconocimiento de la soberanía popular: «las corporaciones que quieran fundar algún establecimiento de segunda enseñanza deberán también obtener para ello autorización expresa del Gobierno, lo cual exigirá los requisitos que se estimen convenientes» (artículo 95).

Tan tarde como en la última década de la era Isabelina, es decir, unos cincuenta años después del Informe de Quintana, y casi treinta años después de llegar el Liberalismo al poder, se consiguió articular una ley que fuera aceptada por las Cortes. El hábil político que lo logró fue el ministro de Fomento Claudio Moyano Samaniego, que recurrió a una estrategia legal y parlamentaria para alcanzar el objetivo. En 1857, antes de que las Cortes se fueran de veraneo, les sometió una Ley de Bases, con sólo tres artículos, autorizando al Gobierno para formar y promulgar una ley de Instrucción Pública. Y a la vuelta del veraneo pudo ser promulgada la Ley de Instrucción Pública de 9 de septiembre de 1857 (M.E.C. 1979, II, 244-302), conocida como Ley Moyano.

Esta Ley contempla todos los niveles de enseñanza, con un enfoque típico del moderantismo (Vega 1998), preocupada ante todo por un desarrollo completo y coordinado de la administración escolar, eliminando del sistema las características sociales más avanzadas que había defendido Quintana, y reconociendo los privilegios y derechos que a la Iglesia se le habían reconocido por el Concordato de 1851. Aunque el Estado controle toda la enseñanza, no se ocupará de financiar más que la enseñanza su- 
perior y profesional; la primaria correrá a cargo de los municipios y de la secundaria se ocuparán las autoridades provinciales.

En cuanto a la enseñanza primaria la declara obligatoria entre seis y nueve años, aunque permite la enseñanza doméstica; reduce su gratuidad a los pobres que no puedan pagarla; reconoce varios tipos de escuela -escuelas elementales completas, elementales incompletas, escuelas de temporada y escuelas superiores- abriendo la puerta oficialmente a la existencia de miles de escuelas con un currículo recortado y un maestro o maestra sin estudios. Pero las diferencias en el currículo no se terminan ahí, pues mientras que un niño de ciudad puede aprender, además de Doctrina Cristiana e Historia Sagrada, lectura, escritura, gramática, principios de aritmética y nociones de agricultura, industria y comercio, una pequeña formación preprofesional (principios de geometría, dibujo lineal y agrimensura, rudimentos de historia y geografía y nociones generales de física e historia natural), una niña también de ciudad se verá privada de los conocimientos de agricultura, geometría, dibujo, física e historia natural, aunque se le «recompense» con «labores propias de su sexo", elementos de dibujo aplicados a esas labores y ligeras nociones de higiene doméstica. Y dado que la única escuela obligatoria en toda población en cuanto reúna quinientos habitantes es la «elemental», los niños y las niñas de las zonas rurales (la mayoría), sin escuela superior, no recibirán el currículo preprofesional. Eso sí, los manuales de la escuela los fijará el Gobierno cada tres años, y también los libros de lectura, procurando que los que se usen, además de inspirarles "sanas máximas religiosas y morales», «les familiaricen con los conocimientos científicos e industriales», pues no en balde la sociedad estaba dirigida por burgueses a los que les interesaba especialmente que los jornaleros y empleados fueran obedientes y estuvieran mejor calificados para su trabajo. Se determinó la creación de una Escuela Normal para maestros en cada capital de provincia, y se anunció que «se procurará que establezcan Escuelas Normales para maestras». Y, de acuerdo con el espíritu centralista de la ley, se creó una Escuela Normal Central en Madrid, en donde se quería impartir un curso superior para «maestros de Escuela Normal e inspectores de primera enseñanza».

La enseñanza secundaria podía seguirse también en el hogar doméstico ${ }^{17}$, y comprendía estudios generales y estudios de aplicación. Los estudios generales, o Bachillerato propiamente dicho, se comenzaban a los nueve años y se estructuraban en dos ciclos: el primero, en el que se impartían materias que venían a ser una sencilla ampliación de las de la escuela; el segundo, en la mejor línea tradicional de la antigua Facultad de Artes, ofrecía unos conocimientos predominantemente de corte huma- 
Vida, fulgor y crisis del sistema escolar español

nista. Habría un instituto en cada capital de provincia, y alguno más en ciudades de muchos habitantes, como Gijón o Vigo, por ejemplo. De ahí que de allí en adelante se situara el número de institutos en España en una cifra cercana a los sesenta, cifra que apenas se modificó hasta la tercera década del siglo XX, mientras que durante la Restauración aumentó considerablemente la enseñanza privada. Por cierto, la libertad de enseñanza de la ley Moyano permitía la creación de establecimientos de segunda enseñanza, siempre que se cumpliera con una serie de requisitos y exigencias académicas, morales y financieras. Solamente se eximió del «título y fianza que exige el artículo 150» a los Jefes y Profesores de los institutos religiosos de ambos sexos «legalmente establecidos en España».

En el nivel académico más alto se situaron las «Universidades», la «enseñanza superior»y las «enseñanzas profesionales». Aunque fueran pocas las cabezas de distrito universitario que tuvieran casi todas, las diez universidades existentes ofrecían diferentes carreras: Farmacia, Medicina, Teología, Derecho (Leyes, Cánones y Administración), Ciencias (exactas, físicas y naturales) y Filosofía y Letras (Lengua, Literatura, Historia y Filosofía). La denominada «enseñanza superior» comprendía los estudios de ingeniería y arquitectura; y las «enseñanzas profesionales» abarcaban estudios de veterinaria, profesorado mercantil, náutica, magisterio, etc. Los estudios de doctorado y el grado de doctor sólo se podía obtener en la Universidad Central, que era la de Madrid

Podemos asegurar que la Ley Moyano dejó atado y bien atado todo el sistema escolar hasta el más mínimo detalle, basándose en un organigrama piramidal y jerárquico que colocaba al frente de la enseñanza al Ministro de Fomento, asistido por un Consejo de Instrucción Pública como órgano asesor, y por la Inspección como institución de control y ejecución. A su vez el Rector ocupaba la jefatura suprema de toda la enseñanza de un distrito universitario, asesorado por un 'Consejo universitario'. Y las Juntas de Instrucción pública provinciales y locales se encargaban de cumplir y hacer cumplir las disposiciones del Ministerio, a la vez que de elevar al mismo las necesidades escolares de sus zonas. $\mathrm{Ni}$ siquiera los programas de las asignaturas universitarias quedaron a la libre iniciativa.

\section{Reformas}

Desde 1857 hasta 1970 no hubo en España otra Ley general de Instrucción Pública, o de Educación si utilizamos términos actuales. Perma- 
neció vigente, pues, o como punto de referencia al menos, más de un siglo entero. Es cierto que a lo largo de esa centuria fue modificada con diversas intenciones y diferentes enfoques en muchas ocasiones, pero no lo es menos que las nuevas disposiciones de menor rango tuvieron a veces vida efímera, y que aunque permanecieran no dejaban de suponer una maraña legislativa intrincada y a veces desconocida, ya que como auténtico espíritu de la administración escolar se reconocía al de la Ley. No obstante, lo peor fue que muchas de las metas que se trazaron Moyano y sus colaboradores en aquella Ley tardaron más de medio siglo en ser cumplidas, y aun otras tantas no se alcanzaron ni después de un siglo entero. Si se hubieran observado las pautas marcadas en la Ley, por ejemplo, hubiera disminuido el analfabetismo de modo notable antes de finalizar el periodo decimonónico, o hubiera desaparecido en la primera mitad del siglo XX (Vilanova y Moreno 1992), o se hubiera escolarizado a gran parte de la población correspondiente antes de la primera guerra mundial, o las condiciones de los espacios (Escolano 2000), los tiempos, los manuales, los métodos o los profesores de las escuelas hubieran tenido el nivel pedagógico de la Europa de la época (Ruiz Berrio 1999).

Pero, como decía, sí que en esos cien años largos se hicieron cambios y se llevaron a cabo reformas del sistema escolar. Se aprobaron leyes y reglamentos, se decretaron órdenes, se emitieron circulares, y se diseñaron muchos más proyectos; pero dados los límites de este escrito y su intencionalidad no interesa el registro/catálogo de unos y otros. Tan sólo voy a recordar algunos de ellos como testimonio de la existencia de pretendidas o reales modificaciones del sistema escolar en aquellos ciento trece años. Por ejemplo, y en primer lugar, se puede citar la efímera Ley de instrucción primaria de Severo Catalina (junio 1868), o los Decretos de Ruiz Zorrilla sobre libertad de enseñanza (octubre 1868) o los revolucionarios planes de Uña y Chaos para el Bachillerato (1873). Después, durante la Primera Restauración se generó para la enseñanza una tupida producción legislativa, pero dada la continua presencia de planes o ideas opuestas, como fruto de la alternancia en el poder de los conservadores y los liberales, su resultado fue pobre por no decir nulo.

Los intentos de actualización y modernización exigidos por el desarrollo industrial en la coyuntura intersecular, mucho más que el pretendido desastre del Noventayocho, provocaron una notable atención de los poderes públicos a las cuestiones de la enseñanza, comenzando por la creación de un Ministerio de Instrucción Pública y Bellas Artes en 1900 (Álvarez Lázaro 2001), y destacando la especial actividad que nada más comenzar este siglo desplegó uno de los titulares de ese nuevo ministerio, D. Álvaro de Figueroa, Conde de Romanones. No es que transformara el 


\section{Vida, fulgor y crisis del sistema escolar español}

sistema escolar, pero hizo algo más positivo, enmendar la pésima situación de muchísimos asuntos del mismo, como lograr que por fin se pagara a los maestros haciéndose cargo el Estado de sus gastos, o que se renovaran los programas de la enseñanza primaria y de la secundaria de acuerdo con el tipo de sociedad que se estaba construyendo en Europa. Hasta el comienzo de la primera Guerra Mundial otros ministros fueron sucesivamente, aunque no de modo sistemático, contribuyendo a ordenar nuestro sistema, renovando o creando diversas instituciones administrativas, científicas y escolares ${ }^{18}$.

Durante la dictadura del general Primo de Rivera se frenaron muchas de las iniciativas docentes y científicas diseñadas o ideadas anteriormente, procurando las autoridades gubernamentales centralizar al máximo el sistema escolar para asegurarse su control, bien minorizando o cerrando presupuestos, o bien decretando medidas como la del «texto único» en el Bachillerato. La falta de sensibilidad social y cultural del dictador jerezano originó, cuando menos, un gran estancamiento en la enseñanza pública, paradójicamente en un tiempo en que la sociedad, viva y creativa, se modernizaba a pasos rápidos en sus comportamientos, en sus mentalidades, en sus apetencias culturales y científicas.

Esa situación de conflicto entre la España oficial y la España real, entre los gobernantes y los gobernados, entre el crecimiento económico y sociocultural, entre un conservadurismo trasnochado y una necesidad popular de ampliar los ámbitos de libertad, fue lo que, junto a otras razones más específicas, condujo a la amplia victoria de las candidaturas republicanas en las grandes poblaciones en las elecciones municipales del 31, e, inmediatamente a la proclamación de la Segunda República española. En el primer bienio de esta República (Molero 1977), con tomas de postura novedosas y con reformas progresistas en la enseñanza, sobre todo en la primaria y en la popular, se despertaron las expectatiras de los españoles en este mundo de la enseñanza y de la cultura, aunte algunas medidas de exclusividad (Rodríguez Coarasa 1998) decretadas, como la prohibición de la enseñanza a las órdenes religiosas bajo cualquier condición, le retiraron el apoyo de un importante sector de la población. La contrarreforma educativa del bienio radical-cedista paralizó de raíz el fruto posible de las medidas innovadoras, atizó el desencuentro de otra mayoría de españoles y cerró el sueño de renovación escolar que se tenía en los años veinte. Las leyes de enseñanza primaria, secundaria y superior que había diseñado Fernando de los Ríos durante su ministerio en Instrucción Pública, para culminar el proyecto reformista del sistema escolar por parte de los primeros republicanos, no llegaron a cobrar vida legislativa, reduciéndose todo el parto de los políti- 
cos a un plan de Bachillerato ecléctico y con lastre (el de Filiberto Villalobos, en 1934).

Obtenida la victoria militar por las tropas del general Franco en 1939, hubo una imposición del nacional-catolicismo en la enseñanza (Cámara 1984) durante los primeros años de la nueva Dictadura, años caracterizados por un claro retroceso en el desarrollo del sistema educativo (Mayordomo y Fernández 1993). El nuevo régimen, liderado por una burguesía terrateniente, se ocupó en primer lugar y ante todo de los estudios de sus hijos, por lo que se aprobó un enésimo nuevo Plan de Bachillerato -el de Sainz Rodríguez (Alted 1984) - antes de terminar la guerra, en 1938, plan clasista, humanista, cíclico, enciclopédico, con la vista puesta en el «pasado glorioso español», con la imposición de una «formación del espíritu nacional» y con un aprendizaje de idiomas modernos de acuerdo con el que se creía entonces próximo imperio de las potencias del Eje. Hasta 1943 no se aprobó una ley para la universidad, y todavía hubo que esperar dos años más para regular las cuestiones de la enseñanza primaria según los criterios del «nuevo Estado».

La situación política internacional al principio de los años cincuenta, y el nuevo valor concedido a España en esa estrategia, obligó a una cierta apertura del régimen y también de la enseñanza. El ministerio de Ruiz Giménez hizo varios intentos en esa línea, y ello permitió que durante las etapas de sus sucesores, especialmente la de Jesús Rubio y García Mina, comenzara la extensión definitiva de la enseñanza primaria y los inicios de la popularización de las enseñanzas medias, mediante la apertura de varias Secciones Delegadas, Secciones Filiales, Estudios Nocturnos, etc.

Tras los Planes de Desarrollo los gobiernos tecnocráticos se empeñaron y consiguieron el despegue industrial de nuestro país, que estimaron sólo podía ser presentable en un contexto moderno de la sociedad en todas sus dimensiones. Tales pretensiones exigieron dedicar una atención pedagógica y social a la enseñanza pública (Puelles 19919) y se consideró que había llegado el momento, después de más de cien años de vigencia, de renovar la Ley Moyano. El Ministerio de Educación elaboró un Libro Blanco en el que se expusieron con bastante crudeza los defectos de nuestra enseñanza a la vez que se esbozaban los nuevos caminos que debía tomar. La Ley General de Educación de 1970, o Ley Villar Palasí, fue la expresión legal de aquellos afanes de desarrollismo económico y escolar, pero fueron más modernas sus intenciones que sus realidades, ya que algunos sectores conservadores del régimen se opusieron firmemente y desactivaron la Ley desde el momento y hora en que la separaron de la normativa de financiamiento que debía acompañarla. 
Vida, fulgor y crisis del sistema escolar español

\section{Crisis}

Es verdad que escribo estos párrafos en un momento en que la Ministra de Educación, Cultura y Deporte ha anunciado que en breves meses someterá a las Cortes para su aprobación una nueva ley sobre el sistema escolar, «Ley de calidad de la enseñanza» según la expresión oficial, y cuyo anteproyecto es aún desconocido. Ello asegura que importantes cambios afectarán al sistema escolar dentro de poco. Pero yo no hablo de crisis por esa información -que también podría hacerlo, por supuesto-. Sino que lo hago en el sentido del punto de partida de este artículo, en el sentido que afecta a los sistemas escolares clásicos en el mundo actual, a todos y no tan sólo a uno de ellos en particular. Si no fuera así, si me preocupara solamente el cambio legislativo que un partido político en el poder puede decidir en virtud de su mayoría absoluta, hablaría de reforma.

Pero considero importante dedicar, aunque sólo sea un párrafo, a ese término de reforma, ya que el abuso del mismo o la falta de clarificación en sus connotaciones mejor dicho, está produciendo en la última década beneficiosas reflexiones en torno a sus características y significados. Son análisis que necesitábamos para ser más rigurosos en la utilización del lenguaje. Y para comprobarlo, no hay que irse muy lejos. Precisamente yo mismo he bautizado el apartado anterior como REFORMAS, sin establecer diferencia alguna entre todas aquellas a las que me he referido. ¿Qué diferencias? ... Pues las que surgen entre reformas que perfeccionan el sistema o las que no lo perfeccionan; entre las que logran cambiar sustancialmente dicho sistema y las que no; entre las que tienen éxito y las que no, etc. Por ejemplo, entre las que he mencionado: ¿podemos atribuir el mismo significado a la Ley de instrucción primaria de Severo Catalina, que suponía una rotunda involución educativa, consumando la desaparición de las Escuelas Normales entre otros retrocesos, que a los Decretos de libertad de enseñanza de Ruiz Zorrilla, que concedía sin cortapisas a los españoles tanto la libertad de creación de centros como la de enseñanza en la cátedra?... En sentido estricto, las dos causan una modificación apreciable del sistema escolar, pero con un sentido muy diferente. Pero hay más, ¿podemos dar tanto a una como a otra, la de junio del 68 o la de octubre del mismo año, la misma importancia por sus efectos que al Decreto de octubre de 1901 del Conde Romanones? O, ¿es que es lo mismo conseguir una duración de tres meses, que de cinco años, que de treinta y seis años ${ }^{19}$ ?

En esta línea creo que es bueno recomendar que los políticos, los comparatistas o los historiadores de la educación, antes de hacer propuestas o antes de valorar las de otros, presentes o pasadas, estudien con deteni- 
miento el carácter polisémico de la palabra reforma y manejen un concepto claro de la misma. O lo que es más, «al referirse a los fines y objetivos de una reforma educativa y la señalización de sus efectos y consecuencias, el historiador debe distinguir entre fines explícitos y fines no declarados o implícitos, incluso en algunas ocasiones negados. Es decir, distinguir entre el discurso teorético de la reforma y los objetivos ocultos cuando se detecten. En este escenario, el éxito o el fracaso no debe ser considerado en relación con los fines expresados, sino más bien con aquellos a los que se aspira pero que no se manifiestan» (Viñao 2002).

Por otro lado, también es conveniente no confundir lo que se puede entender en el mundo académico internacional por reforma ${ }^{20}$, y ser conscientes de que la misma, promovida por instancias políticas, afecta al gobierno y administración de la educación, su estructura o financiación, el contenido, la evaluación del currículo, la enseñanza, la selección o evaluación del profesorado y la evaluación del mismo sistema educativo (Viñao 2002). Sin embargo, no afecta a lo que podemos denominar verdaderamente cambios profundos en la educación, ligados a las grandes innovaciones, como las de las ideas o de los métodos de educación, y promovidos por asociaciones o individuos: método Decroly, pedagogía institucionista, sistema preventivo de Dom Bosco, método de Fröbel, etc.

Una vez apuntadas las distinciones anteriores, creo que es más fácil comprender qué se puede entender por crisis de nuestro sistema escolar. En primer lugar, que no se trata de que sobre el viejo armazón del mismo se hagan arreglos, chapuzas, o apaños, sino que pienso que puede afectar a los mismos principios en que se basa el todopoderoso sistema. Quizá en las reformas llevadas a cabo durante la democracia, la más famosa de las cuales es la que ha supuesto la LOGSE, se ha procurado adaptar el sistema a la nueva situación política que vivía el país, recuperando las décadas de retraso, pero cada vez se pone más de manifiesto que en esos veinticinco años, mientras tanto, ni España ha permanecido inamovible, ni la humanidad ha permanecido quieta. Hasta sería acertado decir que los cambios se han sucedido con un ritmo de progresión geométrica: la evolución de las ciencias, de las técnicas, de las tecnologías, de las gentes y de sus relaciones.

Sin querer entrar a recoger todos esos cambios, sí que podemos mencionar algunos de ellos. En España, por ejemplo, el traslado de varias competencias del Estado a las Autonomías, y especialmente las de la educación; el alargamiento en unos cuantos años de la vida y la calidad alcanzada para varias personas en la llamada tercera edad; el descenso radical del índice de natalidad; el fenómeno de la inmigración en - cantidades que se acercan al millón de personas con otras culturas y 
otras costumbres; el abandono por parte de los españoles de los trabajos manuales, con el tiempo libre que ello deja y las habilidades que en cambio exigen las nuevas actividades; el crecimiento económico con el aumento y la innovación constante de empleos y profesiones que conlleva; la modernización de la infraestructura viaria nacional; el desarrollo espectacular de los mass-media; la puesta en marcha de una sociedad de la información; o la integración de España en una Unión Europea que avanza lenta pero significativamente hacia una sociedad europea integrada en los asuntos económicos, financieros, de enseñanza, de producción de conocimiento, donde los títulos deben estar homologados para que no haya límites a los empleos.

Y si nos fijamos en el mundo del aprendizaje, de la enseñanza, o de la socialización de los niños y jóvenes, comprobamos también que los cambios en este caso se están produciendo a un ritmo trepidante, transformando el papel y las funciones del profesor; ofreciendo la información en cualquier ámbito rural o urbano al mismo tiempo que se produce; disponiendo de varios medios para instruir y también para socializar a los pequeños; o convirtiendo a la educación permanente en el sector más grande, más activo y más importante de la enseñanza. Así el presente y el futuro inmediato, ¿podemos mantener la misma idea del sistema escolar que hace dos siglos, cuando no llegaba a diez el porcentaje de los que sabían leer y escribir, cuando el sistema sirvió para cohesionar una nación, cuando no se podía escolarizar ni a la tercera parte, cuando las primeras maestras no sabían leer ni escribir, cuando no había manuales escolares, cuando la población activa se dedicaba casi exclusivamente a la agricultura y ganadería, cuando el traje de los domingos era para toda la vida, o cuando más del noventa por ciento de los españoles vivían en pequeños pueblos?

Esta es la situación de crisis que digo que afecta al sistema escolar en el momento presente. De los factores que la originan he mencionado sólo unos pocos, unos conocidos ya y otros que desconocemos el «día de antes». Ante ella opino que merecería la pena reconsiderar o reorientar radicalmente el sistema escolar, que ha prestado grandes servicios, a pesar de sus defectos, pero que hace agua por mucho agujeros.

\section{Notas}

1 En una publicación moderna de la UNESCO (1997, paragraph 111-112) se habla del carácter global de la crisis de la humanidad, recordando que «nuestra cultura incluye nuestro sistema completo de creencias, valores, actitudes, costumbres e instituciones. 
Conforma nuestro género, raza y otras relaciones sociales, y afecta al camino que observamos nosotros mismos y el mundo, y a cómo nos interaccionamos con otras gentes y con el resto de la naturaleza. Además, la crisis global frente a la humanidad es un reflejo de los valores colectivos y de los estilos de vida, es, sobre todo, una crisis cultural".

2 Sobre características semejantes o específicas de algunos sistemas escolares europeos en su nacimiento puede verse el artículo de Barreiros (1988).

${ }^{3}$ La fecha más representativa de estas Cortes es la de 1812, porque el 19 de marzo de ese año proclamaron la primera Constitución de España.

4 Fue aprobada el 9 de septiembre de 1857, y es conocida como "Ley Moyano", ya que fue Claudio Moyano el ministro que la propuso y defendió.

${ }^{5}$ Lo que entonces se llamaba las regalías, o prerrogativas del rey, que encarnaba el poder civil.

${ }^{6}$ Durante bastante tiempo se defendió, por ejemplo, que el que conoce el bien lo amará, por lo que se convirtió también la instrucción en fuente de moral.

7 Sobre la constitución de un cuerpo de examinadores para maestros de primeras letras puede consultarse Ruiz Berrio (2001)

${ }^{8}$ Así, por ejemplo, la transformación de la Hermandad de San Casiano en Colegio académico del noble arte de primeras letras en 1780.

$9 \mathrm{Rl}$. Cédula de 12 de julio de 1781.

10 La historiografía de finales del siglo XX hace tiempo que modificó la interpretación clásica de la mal llamada "Guerra de la Independencia", insistiendo en la complejidad e interés de aquellos seis años para la historia posterior de España. El caso de publicación más reciente en este sentido es el libro de Álvarez Junco (2001), especialmente el capítulo III.

11 Se suprimen las facultades jurisdiccionales de los señoríos, sus monopolios, las prestaciones personales, los derechos de caza, pesca, etc., pero se reconoce el «dominio de la tierra", lo que dio carta de naturaleza en el nuevo régimen a la propiedad privada.

12 Para una visión moderna del marco social y cultural de la España del siglo XIX, así como la del XX, puede consultarse, entre otras, la reciente obra de Jover Zamora et al. (2000).

13 En torno al nacimiento e implementación de las nuevas instituciones docentes en los niveles primario y secundario de la enseñanza pueden ampliarse datos en Ruiz Berrio (2002).

14 Conocido como 'Plan del Duque de Rivas', ya que fue este Ministro el que lo aprobó.

15 Pablo Montesino fue el principal inspirador de este plan. Para mayores detalles sobre esta cuestión puede leerse Ruiz Berrio (1990). Sobre su ideario pedagógico ver Montesino (1992).

16 También conocido como «Plan Pidal», ya que éste fue el ministro que lo planteó.

17 No olvidemos que en el Antiguo Régimen los hijos de la nobleza solían realizar los estudios previos a la Universidad en sus hogares, costumbre que imitó también la alta burguesía. Hasta el mismo Rousseau, cuando en 1762 nos lega un plan revolucionario de educación, sitúa a su discípulo, Emilio, en su casa, con un preceptor.

18 Una publicación reciente que aborda capítulos importantes de la educación en España en el siglo pasado es Labrador (2000)

${ }_{19}$ Me permito recordar al lector, que ya lo sabe, que el plan de estudios para la escuela primaria de 26 de octubre de 1901 estuvo vigente en España hasta 1937, en que el Ministro de la zona republicana, Jesús Hernández, decretó un plan distinto.

20 En una obra de hace pocos años Pedró y Puig (1998, p. 44) entienden, siguiendo un criterio actual, que es «un cambio fundamental en las políticas nacionales de educación». 


\section{Vida, fulgor y crisis del sistema escolar español}

\section{Bibliografía}

Alted Vigil, A. (1984): Política del nuevo Estado sobre el patrimonio cultural y la educación durante la guerra civil española. Madrid: Dirección General de Bellas Artes y Archivos.

ÁlvareZ JunCo, J. (2001): Mater dolorosa. La idea de España en el siglo XIX. Madrid: Taurus.

Álvarez LÁZaro, P. (dir.) (2001): Cien años de educación en España. En torno a la creación del Ministerio de Instrucción Pública y Bellas Artes. Madrid: Ministerio de Educación, Cultura y Deporte-Fundación BBVA.

BARREIROS, H. (1988): «Reflexiones en torno al antes y al después de la Revolución de 1789. La constitución de los sistemas educativos contemporáneos». Historia de la Educación, 7, 19-35.

CÁmARA VILlAR, G. (1984): Nacional-catolicismo y escuela. La socialización política del Franquismo (1936-1951). Jaén: Hesperia.

CONDORCET, M. de (2001): Cinco Memorias sobre la Instrucción Pública y otros escritos. Prólogo a la edición española de Narciso de Gabriel. Madrid: Morata.

Escolano Benito, A. (2000): Tiempos y espacios para la escuela. Ensayos históricos. Madrid: Biblioteca Nueva-Colección Memoria y crítica de la educación.

Jovellanos, G. M. de (1963): «Memoria sobre educación pública, o sea Tratado teóricopráctico de la enseñanza con aplicación a las escuelas y colegios de niños». En Obras completas publicadas e inéditas de. Tomo I, pp. 230-267. Madrid: Atlas-Biblioteca de Autorès españoles.

Jovellanos, G. M. de (1963): «Bases para la formación de un Plan general de Instrucción Pública». En Obras completas publicadas e inéditas de. Tomo I, pp. 268-276. Madrid: Atlas-Biblioteca de Autores españoles.

Jover ZAMORA, J. M., GÓMEZ-FERRER, G. y FUSI, J. P. (2000): España: Sociedad, Política y Civilización (siglos XIX-XX). Madrid: Areté-Debate.

LABRADOR, C. (coord.) (2000): La educación en España en el siglo XX. No monográfico extraordinario de Revista de Educación. Madrid: Ministerio de Educación y Ciencia.

MAYORDOMO, A. y FERNÁNDEZ SORIA, J. M.(1993): Vencer y convencer. Educación y política. España 1936-1945. Valencia: Universitat de València.

M.E.C. (1979): Historia de la educación en España. Textos y documentos. Tomo I, Del Despotismo ilustrado a las Cortes de Cádiz; Tomo II, De las Cortes de Cádiz a la Revolución de 1868. Estudio preliminar de Manuel Puelles. Madrid: M.E.C., Secretaría General Técnica.

Molero Pintado, A. (1977): La reforma educativa de la Segunda República española. Primer bienio. Madrid: Santillana.

Montesino, P. (1992): Manual para los maestros de escuelas de párvulos. Introducción crítica de Julio Ruiz Berrio. Madrid: Clásicos CEPE.

NAVAL, C. (1999): «La opción centralizadora del Plan de Estudios de 1845». En LASPALAS PÉrez, J. (ed.): Historia y Teoría de la Educación. Estudios en honor del profesor Emilio Redondo García. (pp. 273-296). Pamplona: EUNSA.

NEGRÍn FAJARDO, O. (1979): «La carta II de F. Cabarrús: una alternativa pedagógica al sistema educativo español de finales del siglo XVIII». Revista de Ciencias de la Educación, XXV, 97, 47-66.

Pedró, F. y PUIG, I. (1998): Las reformas educativas. Una perspectiva política y comparada. Barcelona: Paidós. 


\section{Julio Ruiz Berrio}

Puelles Benítez, M. (1991): Educación e ideología en la España contemporánea. (3ª edición). Barcelona: Labor.

Puelles Benítez, M. (1997): «Incidencia de los factores políticos en la génesis y configuración del sistema educativo español (1809-1836). En Escolano, A. y Fernández, R. (eds.): Los caminos hacia la modernidad educativa en España y Portugal (18001975). Zamora: Fundación Rei Afonso Henriques.

RODRíguez CoARASA, C. (1998): La libertad de enseñanza en España. Madrid: Tecnos.

RUIZ BerRio, J. (1970): Política escolar de España en el siglo XIX (1808-1833). Madrid: C.S.I.C.

RUIZ BERRIO, J. (1983): «El plan de reforma educativa de un afrancesado: el de Manuel J. Narganes de Posada". Historia de la Educación, 2, 7-18.

RUIZ BERRIO, J. (1990): «Una formación europea para un reformador español, Pablo Montesino". Revista Complutense de Educación, 3, 427-434.

RUIz BERRIO, J. (1994): «El pensamiento pedagógico. 1. Manuel José Narganes de Posada». En Delgado, B. (coord.): La educación en la España contemporánea (1789-1975), tomo III de la Historia de la Educación en España y América (pp. 110-114). Madrid: Ediciones S.M.-Ediciones Morata.

RUIZ BERRIO, J. (1999): «La enseñanza en vísperas del 98. Rasgos y orígenes». En RUIZ Berrio, J., Bernat, A., Domfnguez, M. R. y JuAN, V. M. (eds.): La Educación en España a examen (1898-1998). (Vol. II, pp. 307-320). Zaragoza: Ministerio de Educación y Cultura-Institución "Fernando el Católico».

RUIZ BERRIO, J. (2001): "La acreditación de los saberes de los maestros en el Antiguo Régimen, ¿solvencia profesional, poder o control?». En XI Coloquio Nacional de Historia de la Educación, La acreditación de saberes y competencias. Perspectiva histórica (pp. 720-730). Oviedo: Sociedad española Historia de la Educación-Universidad de Oviedo.

RUIZ BERRIO, J. (2002): «El sistema educativo español. De las Cortes de Cádiz a la Ley Moyano". En OSSENBACH, G., TIANA, A. et al.: Historia de la Educación en España. Madrid: UNED.

UNESCO (1997): Educating for a Sustainable Future: A Transdisciplinary Vision for Concerted Action.

VEGA GIL, L. (coord.) (1998): Moderantismo y educación en España. Estudios en torno a la Ley Moyano. Zamora: Instituto «Florián de Ocampo».

VIlanova, M. y MORENo, X. (1992): Atlas de la evolución del analfabetismo en España de 1887 a 1981. Madrid: C.I.D.E.

VIÑAo Frago, A. (1996): “Antonio Gil de Zárate». En RUIZ BERRIO, J. (dir.): La educación en España. Textos y documentos. (pp. 136-140). Madrid: Actas Editorial.

VIÑAO FRAGO, A. (2002): "Do education reforms fail? a historian's response». Encounters. Encuentros. Encontres, 2. 